\title{
Frequency, Levels and Predictors of Potential Drug-Drug Interactions in a Pediatrics Ward of a Teaching Hospital in Pakistan
}

\author{
Mohammad Ismail $^{1}$, Zafar Iqbal ${ }^{1^{*}}$, Muhammad I Khan ${ }^{2}$, Arshad Javaid $^{3}$, Hassan \\ Arsalan $^{4}$, Farhadullah ${ }^{4}$, Faramoz Khan ${ }^{5}$, Amir Z Khan ${ }^{1}$, Fazli Nasir ${ }^{1}$ and \\ Jamshaid A Khan ${ }^{1}$ \\ ${ }^{1}$ Department of Pharmacy, University of Peshawar, Peshawar, ${ }^{2}$ Ayub Medical College, Abbottabad, Khyber Pakhtunkhwa, ${ }^{3}$ Post \\ Graduate Medical Institute, Lady Reading Hospital (LRH), Peshawar, ${ }^{4}$ Department of Pharmacy, Sarhad University of Science \\ \& Information Technology, Peshawar ${ }^{5}$ Medical-B Unit, Khyber Teaching Hospital, Peshawar, Pakistan.
}

*For correspondence: Email: zafar_iqbal@upesh.edu.pk; Tel: +92-91-9216750; Fax: +92-91-9218131

Received: 13 August 2012

Revised accepted: 16 April 2013

\begin{abstract}
Purpose: To identify the frequency, levels and predictors of potential drug-drug interactions ( $p D D / s)$ in a pediatrics ward of a teaching hospital in Pakistan.

Methods: Medication profiles of 400 pediatric patients were evaluated for $p D D / s$ using Micromedex Drug-Reax® software. Logistic regression was used to identify association of pDDIs with hospital-stay, patient's gender, and number of medications.

Results: In total, 86 interacting drug-combinations resulting in 260 pDDls were identified. Overall, 25.8 $\%$ patients were exposed to at least one $p D D I$ regardless of severity-type, $10.7 \%$ to at least one major$p D D I, 15.2 \%$ to at least one moderate-pDDI, and $12.5 \%$ to at least one minor-pDDI. Of 260 pDDIs, most were of moderate severity (41.5\%) followed by minor (35.4\%) and major severity (21.9\%); good $(76.9 \%)$ or fair (16.5\%) type of scientific evidence; and delayed onset (46.5\%). Some widespread major or moderate interactions included rifampin + pyrazinamide (14 cases), phenobarbital + diazepam (14), dexamethasone + rifampin (8), amikacin + furosemide (7), furosemide + captopril (7), dexamethasone + phenobarbital (6), phenobarbital + divalproex sodium (6), isoniazid + rifampin (5) amikacin + ibuprofen (5), digoxin + furosemide (4), and acetaminophen + phenytoin sodium (4). There was significant association of the occurrence of $p D D / s$ with five or more prescribed medications $(p<$ 0.001).

Conclusion: PDDIs are less prevalent in the pediatrics ward of the hospital studied. Most of the interactions were of moderate severity. Patients with increased number of prescribed medications were more exposed to these interactions.
\end{abstract}

Keywords: Drug-drug interactions, Prescription screening, Drug related problems.

Tropical Journal of Pharmaceutical Research is indexed by Science Citation Index (SciSearch), Scopus, International Pharmaceutical Abstract, Chemical Abstracts, Embase, Index Copernicus, EBSCO, African Index Medicus, JournalSeek, Journal Citation Reports/Science Edition, Directory of Open Access Journals (DOAJ), African Journal Online, Bioline International, Open-J-Gate and Pharmacy Abstracts

\section{INTRODUCTION}

Recent developments in pharmacotherapy have contributed considerably to improve patients' quality of life. As a result of such advancement, the number of available medications and their uses are increasing. Although drugs are used to achieve beneficial therapeutic effects, they can also lead to many undesirable consequences. One of such consequences is the problem of potential drug-drug interactions (pDDIs) that may 
lead to alteration of therapeutic response or increase in untoward effects of many drugs $[1,2]$.

A wide variation exists in the prevalence of pDDIs in hospital settings due to differences in the design of research studies. Prevalence of pDDIs has been reported in the range of 19.3 to $88.8 \%[3,4]$. A study, conducted in two hospitals in England, found that 1225 (6.5\%) hospital-admissions were caused by medicines, of which, 203 (16.6\% of 1225) admission were related to drug-interactions [5]. A review paper analyzed published literature related to drug related problems (DRPs) in hospitals. It was reported that during hospitalization, $17 \%$ of all adverse drug events are caused by drug-drug interactions [6].

Some studies have investigated pDDls in particular clinical situations or specialties such as cardiology [7], oncology [8], psychiatry [9], intensive care units [10], pulmonology [11], and geriatrics [12]. Most of the aforementioned studies are limited to adult patients. To the best of our knowledge, such data are scarce in pediatrics specialty. It has been pointed out that hospitalized pediatrics patients are at higher risk to drug-induced problems because of many factors such as wide-ranging of patient ages and body-weights, limited physiologic reserve, calculation errors in medications dosing, and incapability to properly communicate with healthcare professionals [13]. In such circumstances, pDDIs are more likely to cause adverse outcomes in pediatrics hospitalized patients. Therefore, studies are obligatory to report data regarding pDDIs in such an important population.

The present study aimed to find prevalence and levels of pDDIs in a pediatrics ward; their association with length of hospital-stay, patients' gender, and number of prescribed medications; and to determine widespread interacting drugcombinations.

\section{METHODS}

This study was carried out in pediatrics ward of Khyber Teaching Hospital, Peshawar, Pakistan, which is a 1200-bed teaching hospital. The hospital is a busy health care center along with referral services. It serves a population of about 350 thousand inhabitants of Jamrud Road and adjacent areas of Peshawar district.

The study was approved by Ethical Committee of the Department of Pharmacy, University of Peshawar. A cross-sectional design was used which involved evaluation of medical records of
400 patients admitted during the month of May July 2011. Hospitalized patients, < 18 years old, suffering from any type of disease, and both males and females were included in this study. Permission was obtained from hospital administration to carry out this study in hospital. The following information items were collected: patient's age, gender, date of admission, date of discharge, diagnosis and detail of medication therapy provided in the hospital. All regular and PRN (pro-re-nata, means as required) medications were included, however, topical products such as creams, ointments, eye drops and ear drops were excluded from analysis.

Micromedex Drug-Reax® Software (Thomson Reuters Healthcare Inc., Greenwood Village, Colorado, United States) [14], was used to screen patients' medication profiles for pDDIs. The software displays all drug-interactions present in the patient's profile. As per classification of Micromedex Drug-Reax ${ }^{\circledR}$ System [14], all identified-pDDIs were categorized on the basis of their levels of severity, onset, and scientific evidence as follows:

\section{Onset}

- Rapid: The effect of interaction occurs within 24 hours of administration.

- Delayed: The effect occurs if the interacting combination is administered for more than 24 h, i.e., days to week(s).

\section{Severity}

- Contraindicated: The drug-combination is contraindicated for concurrent use.

- Major: There is risk of death and/or medical intervention is required to prevent or minimize serious negative outcomes.

- Moderate: The effect of interaction can deteriorate patient's condition and may require alteration of therapy.

- Minor: Little effects are produced that don't impair therapeutic outcome and there is no need of any major change in therapy

Scientific evidence (Documentation)

- Excellent: The interaction has been clearly demonstrated in well-controlled studies.

- Good: Studies strongly suggest that the interaction exists except proof of wellcontrolled studies.

- Fair: Available evidences are poor, but the interaction is suspected on the basis of pharmacologic considerations; or, evidences are good for an interaction of pharmacologically similar drug.

- Poor: Theoretically, the interaction may occur but reports are very limited, such as few case reports. 
- Unlikely: Data are very poor and lack a proper pharmacologic basis.

Prevalence of pDDIs, belong to any of the severity-levels (overall-prevalence), was identified. Likewise, number of patients exposed to different types of pDDls such as contraindicated-pDDIs, major-pDDIs, moderatepDDIs and minor-pDDIs, were determined. All identified pDDIs were categorized on the basis of their levels of severity, onset, and scientific evidence.

\section{Statistical analyses}

Quantitative variables such as age, hospital stay and number of prescribed medications are presented as median and ranges. Categorical variables such as gender, prevalence and levels of pDDIs are presented as frequencies and percentages. Logistic regression technique was used to determine the association of occurrence of one or more pDDls with length of hospital stay, patients' gender, and number of prescribed medications. In the model, exposure to potential drug-drug interactions (pDDls) was the dependent variable $(0=$ absent, $1=$ present $)$. Whereas, the following variables were included as predictors of pDDIs: length of hospital stay (1 = less than 5 days, $2=5$ days or above), patient's gender $(1=$ female, $2=$ male $)$, and number of prescribed medications $(1=$ less than $5,2=5$ or above). Initially a univariate analysis was performed followed by multivariate analysis, in which, variables with univariate $p$-values $<0.1$ were included. The Hosmer-Lemeshow test was used to assess goodness-of-fit of the logistic regression model. $P$-value of 0.05 or less was considered statistically significant. SPSS for Windows version 16 (SPSS, Inc., Chicago, IL, USA) was used for all statistical analyses.

\section{RESULTS}

Of the total 400 patients, $254(63.5 \%)$ were males and $146(36.5 \%)$ were females. Median age was 1.5 years, median hospital stay was four days and median number of prescribed medications were four (Table 1). One hundred and three $(25.8 \%)$ had at least one pDDI regardless of type of severity (Table 2). As far as prevalence of pDDIs on the basis of severity was concerned, moderate pDDIs were most prevalent and recorded in $15.2 \%$ patients followed by minor pDDIs (12.5\%).

The levels of onset, severity and scientific evidence (documentation) for the identified
pDDIs are given in Table 3. Of 260 pDDIs, most were of moderate severity $(41.5 \%)$ followed by minor $(35.4 \%)$ and major severity $(21.9 \%)$; good $(76.9 \%)$ or fair $(16.5 \%)$ type of scientific evidence; and delayed onset (46.5\%).

Table 1: General characteristics of patients in the pediatric ward

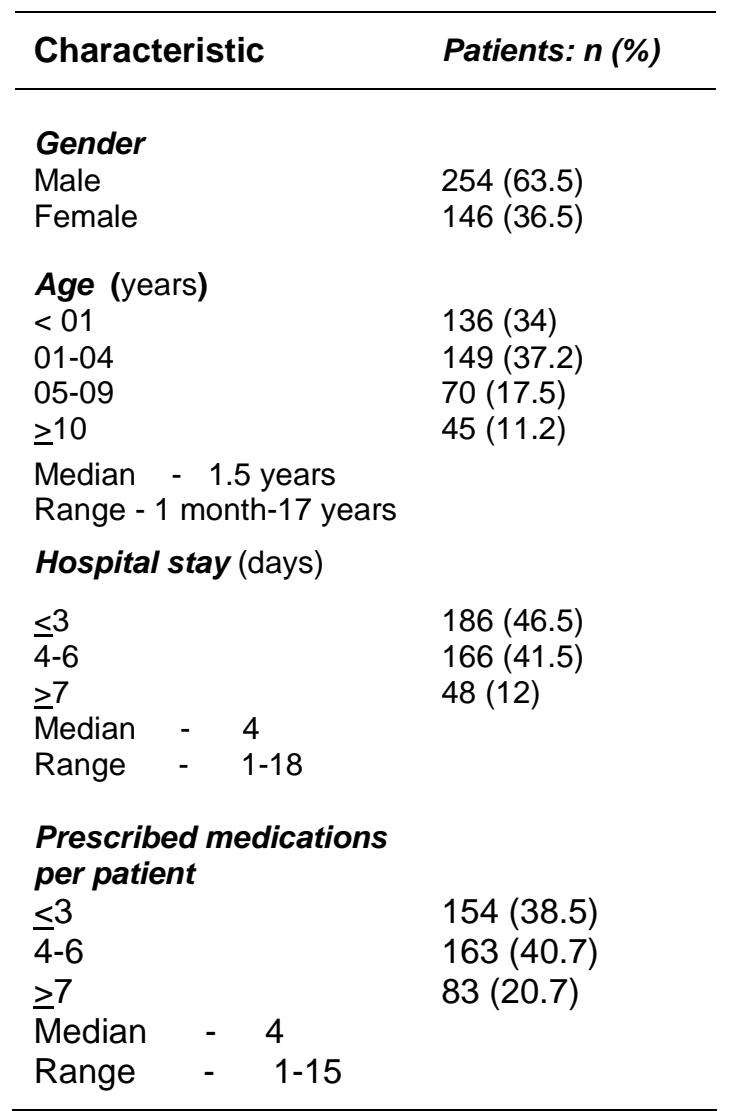

Table 2: Prevalence of potential drug-drug interactions in a pediatric ward

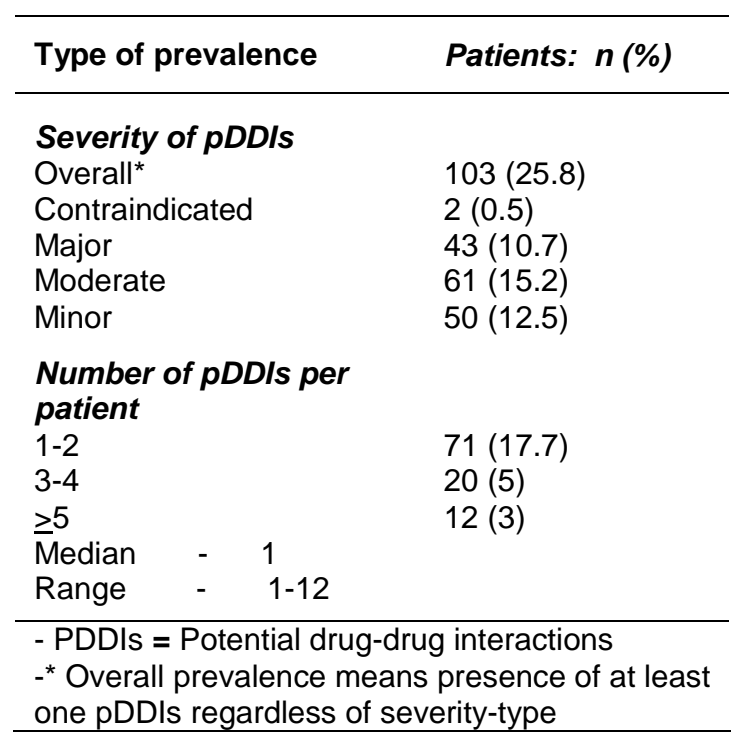


Table 3: Levels of potential drug-drug interactions in a pediatric ward

\begin{tabular}{|c|c|c|}
\hline \multirow[t]{2}{*}{ Level } & $\begin{array}{l}\text { Frequency } \\
\text { in } 86 \\
\text { interacting } \\
\text { drug- } \\
\text { pairs }\end{array}$ & $\begin{array}{l}\text { Frequency } \\
\text { in } 260 \\
\text { pDDIs }\end{array}$ \\
\hline & $\mathrm{n}(\%)$ & n (\%) \\
\hline \multicolumn{3}{|l|}{ Severity } \\
\hline Contraindicated & 2 (2.3) & $3(1.2)$ \\
\hline Major & $15(17.4)$ & $57(21.9)$ \\
\hline Moderate & $53(61.6)$ & 108 (41.5) \\
\hline Minor & $16(18.6)$ & $92(35.4)$ \\
\hline \multicolumn{3}{|l|}{ Documentation } \\
\hline Excellent & $11(12.8)$ & $17(6.5)$ \\
\hline Good & $49(57)$ & 200 (76.9) \\
\hline Fair & $26(30.2)$ & $43(16.5)$ \\
\hline \multicolumn{3}{|l|}{ Onset } \\
\hline Rapid & $23(26.7)$ & $112(43.1)$ \\
\hline Delayed & $53(61.6)$ & $121(46.5)$ \\
\hline Not specified & $10(11.6)$ & $27(10.4)$ \\
\hline \multicolumn{3}{|c|}{$\begin{array}{l}-P D D l s=\text { Potential drug-drug interactions } \\
-^{*} \text { In pediatric ward, } 86 \text { interacting drug-combinations } \\
\text { were identified that encountered in total number of } 260 \\
\text { pDDIs. }\end{array}$} \\
\hline
\end{tabular}

In this study, 86 potential interacting drugcombinations were identified. The top 14 frequently occurring interacting drug-pairs included four major, seven moderate and three minor types of pDDIs. These 14 interacting drugpairs encountered in 155 pDDls (59.6\% of 260 ), while rest of 72 interacting drug-pairs presented in the remaining $40.3 \%$ pDDls. Frequencies of some widespread interacting drug-combinations are given in Table 4.

In univariate logistic regression analysis (Table 5), there was significant association of the occurrence of pDDls with hospital stay of five days or longer $(\mathrm{OR}=1.92 ; 95 \% \mathrm{Cl}=1.21-3.04$; $p<0.01$ ), female gender (OR for male $=0.63 ; 95$ $\% \mathrm{Cl}=0.39-0.99 ; p=0.047)$, and five or more number of prescribed medications (OR $=7.34$; $95 \% \mathrm{Cl}=4.37-12.32 ; p<0.001)$. In multivariate analysis (Table 5), association was significant only in case of five or more number of prescribed medications $(\mathrm{OR}=6.82 ; 95 \% \mathrm{Cl}=4.0-11.59 ; p$ $<0.001$ ).

\section{DISCUSSION}

In the present study, prevalence and nature of pDDIs have been reported in 400 pediatric hospitalized patients. Total 86 interacting drugcombinations were identified that encountered in 260 pDDls. Overall, $25.8 \%$ patients were exposed to at least one pDDI regardless of severity-types, $10.75 \%$ to at least one major pDDI, $15.25 \%$ to at least one moderate pDDI, and $12.5 \%$ to at least one minor pDDI. In comparison to other clinical settings, overall prevalence of pDDls in pediatrics $(25.8 \%$ ) was lower than that reported by many other studies ranging from $37 \%$ to $50 \%$ in whole hospital settings [15,16]; $77.5 \%$ in cardiology [7], $48 \%$ in internal medicine [17], $58 \%$ in oncology [8], 64.8 $\%$ in psychiatry [9], $70 \%$ in intensive care units [10], and $45 \%$ in pulmonology [11]. Results of the present study suggest that pDDls are less prevalent in pediatrics ward as compared with other wards and specialties such as cardiology, internal medicine, oncology, psychiatry, intensive care units and pulmonology.

Table 4: Frequencies of interacting drugcombinations

\begin{tabular}{lc}
\hline Interaction & Frequency \\
\hline Major interactions & \\
Rifampin + pyrazinamide & 14 \\
Phenobarbital + diazepam & 14 \\
Amikacin + furosemide & 7 \\
Isoniazid + rifampin & 5 \\
Quinine + rifampin & 3 \\
Artemether/lumefantrine + quinine & 3 \\
Calcium carbonate + digoxin & 2 \\
Theophylline + ciprofloxacin & 2 \\
& \\
Moderate interactions & \\
Dexamethasone + rifampin & 8 \\
Furosemide + captopril & 7 \\
Phenobarbital + divalproex sodium & 6 \\
Dexamethasone + phenobarbital & 6 \\
Amikacin + ibuprofen & 5 \\
Digoxin + furosemide & 3 \\
Acetaminophen + phenytoin sodium & 4 \\
Phenytoin sodium + diazepam & 3 \\
Furosemide + ibuprofen & 3 \\
Dexamethasone + phenytoin sodium & 3 \\
Ciprofloxacin + zinc & 3 \\
Rifampin + divalproex sodium & 3 \\
Minor interactions & \\
Amikacin + cloxacillin sodium & 3 \\
Pmikacin + ampicillin & \\
Iron + antacid & 3 \\
& 3 \\
Phenytoin sodium + phenobarbital & 3 \\
\hline
\end{tabular}


Table 5: Logistic regression analysis

\begin{tabular}{|c|c|c|c|c|c|c|}
\hline \multirow[b]{2}{*}{ Variable } & \multicolumn{2}{|c|}{ Patients: $n$} & \multicolumn{2}{|c|}{ Univariate } & \multicolumn{2}{|c|}{ Multivariate } \\
\hline & $\begin{array}{r}\text { Interaction } \\
\text { present } \\
(n=103) \\
\end{array}$ & $\begin{array}{r}\text { Interaction } \\
\text { absent } \\
(n=297) \\
\end{array}$ & OR $(95 \% \mathrm{Cl})$ & $p$-value & $\begin{array}{l}\text { OR }(95 \% \\
\mathrm{Cl})\end{array}$ & $\begin{array}{r}p- \\
\text { value }\end{array}$ \\
\hline $\begin{array}{l}\text { Hospital stay (days } \\
<5 \\
\geq 5\end{array}$ & $\begin{array}{l}57 \\
46\end{array}$ & $\begin{array}{r}209 \\
88\end{array}$ & $\begin{array}{r}1.92(1.21- \\
3.04)\end{array}$ & $<0.01$ & $\begin{array}{r}1.25(0.75- \\
2.08)\end{array}$ & 0.396 \\
\hline $\begin{array}{l}\text { Gender } \\
\text { Female } \\
\text { Male }\end{array}$ & $\begin{array}{l}46 \\
57\end{array}$ & $\begin{array}{l}100 \\
197\end{array}$ & $\begin{array}{r}0.63(0.39- \\
0.99)\end{array}$ & 0.047 & $\begin{array}{r}0.74(0.45- \\
1.23)\end{array}$ & 0.246 \\
\hline $\begin{array}{l}\text { Number of drugs } \\
<5 \\
\geq 5\end{array}$ & $\begin{array}{l}24 \\
79\end{array}$ & $\begin{array}{r}205 \\
92\end{array}$ & $\begin{array}{r}7.34 \text { (4.37- } \\
12.32)\end{array}$ & $<0.001$ & $\begin{array}{r}6.82(4.0- \\
11.59)\end{array}$ & $<0.001$ \\
\hline
\end{tabular}

-OR = Odds ratio; $\mathrm{Cl}=$ Confidence interval.

- Exposure to potential drug-drug interactions ( $\mathrm{pDDIs})$ was the dependent variable in the model $(0=$ absent, $1=$ present). The following variables were included in the model as predictors of pDDIs: hospital stay $(1=$ less than 5 days, $2=5$ days or above), patient's gender ( $1=$ female, $2=$ male $)$, and number of drugs $(1=$ less than $5,2=$ 5 or above).

-Hosmer-Lemeshow goodness-of-fit test: $p=0.87$

As far as levels of pDDIs are concerned, our study shows that most of the interactions were of moderate severity $(41.5 \%)$ followed by minor (35.4\%) and major severity (21.9\%); good (76.9 $\%)$ or fair $(16.5 \%)$ type of scientific evidence; and delayed onset $(46.5 \%)$. Similar findings have been reported by other studies, conducted in other wards or specialties $[17,18]$. A study identified total 402 pDDIs in clinical records of 500 patients, of which, most were of moderate severity (70 \%), good scientific evidences $(69.4 \%)$ and delayed onset (89.8\%) [17].

Clinical records of 407 patients were evaluated for pDDIs. Total 276 pDDIs were identified, of which, most pDDls were having moderate severity $(77 \%)$ and good scientific evidences (40 \%) [18]. The aforementioned discussion shows that results of our study are consistent with published literature. Moreover, the list of interacting drug-combinations, particularly widespread major and moderate interactions, will be helpful for health care professionals to screen patients' profiles for pDDIs. This will improve practice regarding the management of pDDIs in clinical settings.

The results of this study show that patients with five or more number of prescribed medications were found to be more exposed to pDDIs (OR = $6.82 ; 95 \% \mathrm{Cl}=4.0-11.59 ; p<0.001)$. These results are in agreement with many other published reports $[3,8,10,12,15,18]$. It is recommended that patients with increased number of medications should be properly monitored for pDDls in order to prevent and minimize the negative consequences of these interactions.

\section{Limitations of the study}

In the present study, only potential drug-drug interactions were investigated. Further work will be required to identify the actual effects of these interactions. This study was conducted in a tertiary care hospital of Khyber Pakhtunkhwa province of Pakistan. Therefore, the findings may not be generalizable to hospitals elsewhere in Pakistan. However, we expect a similar pattern in pediatric wards of other tertiary care hospitals.

\section{CONCLUSION}

PDDIs were less prevalent in pediatrics ward. Most of the interactions were of moderate severity. Patients with increased number of prescribed medications were more exposed to these interactions. Due to sensitive nature of pediatric population, close monitoring is recommended for detection and management of pDDls.

\section{ACKNOWLEDGEMENT}

The authors are very grateful to University of Peshawar for financial support; and to the administration, consultants and all other staff of Khyber Teaching Hospital, Peshawar, for administrative support. 


\section{REFERENCES}

1. Hartshorn EA. Drug interaction: 1. General considerations. Ann Pharmacother 2006; 40: 116 118.

2. Cremades J, Gonzalo M, Arrebola I. Relationship between drug interactions and drug-related negative clinical outcomes. Pharmacy Practice 2009; 7: 34-39.

3. Reimche $L$, Forster AJ, van Walraven C. Incidence and contributors to potential drug-drug interactions in hospitalized patients. J Clin Pharmacol 2011; 51 1043-1050.

4. Straubhaar $B$, Krahenbuhl $S$, Schlienger RG. The prevalence of potential drug-drug interactions in patients with heart failure at hospital discharge. Drug Saf 2006; 29: 79-90.

5. Pirmohamed M, James $S$, Meakin S, Green C, Scott AK, Walley TJ, Farrar K, Park BK, Breckenridge AM. Adverse drug reactions as cause of admission to hospital: prospective analysis of 18820 patients. BMJ 2004; 329: 15-19.

6. Krahenbuhl-Melcher $A$, Schlienger $R$, Lampert $M$, Haschke M, Drewe J, Krahenbuhl S. Drug-related problems in hospitals: a review of the recent literature. Drug Saf 2007; 30: 379-407.

7. Ismail M, Iqbal Z, Khattak MB, Javaid A, Khan MI, Khan TM. Potential drug-drug interactions in cardiology ward of a teaching hospital. Healthmed 2012; 6: 1618-1624.

8. van Leeuwen RW, Swart EL, Boven E, Boom FA, Schuitenmaker MG, Hugtenburg JG. Potential drug interactions in cancer therapy: a prevalence study using an advanced screening method. Ann Oncol 2011; 22: 2334-2341.

9. Ismail M, Iqbal Z, Khattak MB, Javaid A, Khan MI, Khan TM, Asim SM. Potential Drug-Drug Interactions in Psychiatric Ward of a Tertiary Care Hospital: Prevalence, Levels and Association with Risk Factors. Trop J Pharm Res 2012; 11: 289-296.
10. Reis AM, Cassiani SH. Prevalence of potential drug interactions in patients in an intensive care unit of a university hospital in Brazil. Clinics (Sao Paulo) 2011; 66: 9-15.

11. Ismail $M$, lqbal $Z$, Khattak MB, Javaid $A$, Khan TM. Prevalence, types and predictors of potential drugdrug interactions in pulmonology ward of a tertiary care hospital. Afr J Pharm Pharmacol 2011; 5: 1303-1309.

12. Hoffmann $W$, van den Berg $N$, Thyrian JR, Fiss $T$. Frequency and determinants of potential drug-drug interactions in an elderly population receiving regular home visits by GPs--results of the home medication review in the AGnES-studies. Pharmacoepidemiol Drug Saf 2011; 20: 13111318.

13. Wang JK, Herzog NS, Kaushal R, Park C, Mochizuki C, Weingarten SR. Prevention of pediatric medication errors by hospital pharmacists and the potential benefit of computerized physician order entry. Pediatrics 2007; 119: e77-85.

14. Micromedex Drug-Reax® System. [database on CDROM].Volume 150. Greenwood Village, Colo: Thomson Reuters (Healthcare) Inc. 2011.

15. Moura CS, Acurcio FA, Belo NO. Drug-drug interactions associated with length of stay and cost of hospitalization. J Pharm Pharm Sci 2009; 12: 266 272.

16. Cruciol-Souza JM, Thomson JC. A pharmacoepidemiologic study of drug interactions in a Brazilian teaching hospital. Clinics (Sao Paulo) 2006; 61: 515-520.

17. Egger SS, Drewe J, Schlienger RG. Potential drug-drug interactions in the medication of medical patients at hospital discharge. Eur J Clin Pharmacol 2003; 58: 773-778.

18. Riechelmann RP, Tannock IF, Wang L, Saad ED, Taback NA, Krzyzanowska MK. Potential drug interactions and duplicate prescriptions among cancer patients. J Natl Cancer Inst 2007; 99: 592600. 